\title{
15
}

\section{Translating Scientific Results: Encouraging Reflective Policies as a Chance for Change}

\author{
Sorin Cebotari, Tomas Hanell and Thilo Lang
}

\section{Introduction}

Writing a policy recommendation chapter is both challenging and rewarding at the same time. On one hand, it requires us to translate complex academic research into practical policy suggestions. On the other hand, it offers an understanding of purpose for the researcher since a policy chapter is one of the few gates through which social scientists can contribute to shaping a policy discourse. Given this context, our main aim is to formulate clear and comprehensible policy recommendations drawing from the existing academic debate and research presented in the previous chapters.

While the results of processes of polarisation and peripheralisation are mostly visible in remote, isolated or excluded spaces, the dynamics fuelling these processes connect to all levels of policy-making.

\section{S. Cebotari $(\bowtie)$}

Research Center for Sustainable Development, Faculty of Geography, Babeș-Bolyai University, Cluj-Napoca, Romania 
It is important, therefore, to consider policy-making, in this context, as a collection of processes which transcend sectoral and administrative boundaries in a multi-actor setting. Given that understanding, we would like to highlight three distinct administrative levels on which the problem of uneven spatial development is tackled. Firstly, the EU level strikes as the one where the polarisation problem is highly debated and triggers policy action across different EU level actors and institutions. Through the mechanisms of Cohesion Policy, and lately also including some mechanisms of innovation policy (see Loewen and Schulz as well as Telle, Špaček and Crăciun), EU level policy-makers aim to address existing regional discrepancies. While this discussion at the EU policy level is clearly getting more and more attention (see Jones et al.), national states retain the sovereignty to decide upon how to redistribute EU and national funding to tackle peripheralisation. Member states' interest in keeping financial management tools at their disposal is down to a number of reasons. However, it is clear that by doing so, member states also ensure a possibility to shift EU policy goals to their own, national political aims. In this respect, especially in the case of CEE countries, a series of different policies emerged with the main (or at least declared) goal of reducing spatial and income inequalities and promoting even development (see Benedek, Varvari and Litan as well as Posfai and Jelinek). While not with the same amount of political and economic power, regional and local levels offer us the possibility to see the way in which policies (EU or national) interact with local communities and decision makers. In this way, we can see these policies in action (or inaction) (see Moldovan, Cebotari and Mihály, Graffenberger as well as PlüschkeAltof and Grootens). To a certain degree, all these administrative levels

\section{T. Hanell}

University of Helsinki, Helsinki, Finland

T. Lang

Leibniz Institute for Regional Geography, Leipzig, Germany

T. Lang

Global and European Studies Institute, University of Leipzig,

Leipzig, Germany 
are connected through the policy framework. It is important, therefore, to observe how each level of policy making and policy implementation evolves, but at the same time to consider all of them inter-linked and dependent upon each other.

The first three sections of this chapter discuss the main shortcomings and possible improvements of existing public policies at the EU, national and combined, regional and local level. Based on this discussion, the final section outlines five policy recommendations to address rising polarisation and peripheralisation at both the EU and the member state level.

\section{Polarisation Viewed by EU Policy-Makers}

There is growing interest among researchers in EU-level policies that aim to improve territorial cohesion, thus reducing socio-economic disparities within the EU. This book, while looking at specific contexts mostly from Central and Eastern Europe, has several chapters that discuss the EU policy framework, identifying a series of challenges related to Cohesion Policy and subsequent successful implementation of territorial cohesion goals.

One of the serious issues with Cohesion Policy, as discussed by Jones et al., is the fact that, while it is a well-intended policy, territorial cohesion remains an elusive and complex concept. This elusive character of the concept leaves it open to different interpretations, thus it is often misused or manipulated in order to promote specific (or even different) priorities in different national/regional contexts. Even at the level of the European Union, it seems that Cohesion Policy lacks consistency and, therefore, a clear understanding of the pursued goals. It is true that continuous changes in the policy are required given the varying national contexts, thus we end up having different programme goals in different states to suit local needs. At the same time, there must be an over-arching understanding of what Cohesion Policy aims at. Probably the top-rating priorities are to design a consistent policy and to avoid having a series of place-based cohesion policies with different local understandings of programme goals (Telle, Špaček and Crăciun). Another shortcoming of Cohesion Policy is its convergence with innovation policies as presented 
by Loewen and Schulz. The authors stress that convergence between the two policies can lead to the over-centralisation of management authorities at the national level. This in turn would offer national authorities control over the selection and implementation of projects. Given the availability of material and knowledge resources in metropolitan and urban centres, this type of management would benefit the core regions within CEE countries. Although well intentioned and timely thought, this convergence can in this way decrease the positive effects of Cohesion Policy by re-orienting it towards strict economic development, thus neglecting its moderating force across the EU. Based on these observations, we can see that Cohesion Policy remains an elusive and complex concept which can lead to different interpretations by different national authorities. Its convergence with innovation policies makes it more prone to local misinterpretations that in the end might steer Cohesion Policy away from the territorial convergence goal altogether.

Given these major challenges, we believe that EU level policy-makers have to consider a series of changes within Cohesion Policy in order to ensure its efficiency and keep it focused on the reduction of socioeconomic disparities across the EU. One important measure in this direction would be a better conceptualisation of Cohesion Policy goals. A clear outline of what Cohesion Policy means and what it is expected to deliver would help national policy-makers produce better mechanisms of fund management and resource allocation. Further clarification of the policy's goals should look at how it was meant to interact with other policies (for our discussion considering innovation policy). There must be a clear separation between Cohesion Policy and any other policy working in a similar direction. For example, although innovation policy could and should serve as possible mechanism to promote economic development, it should not overshadow the social and environmental goals underlined in Cohesion Policy. In this way, Cohesion Policy needs to be updated such that it adds more clarity regarding its goals and objectives. When reconsidering Cohesion Policy at both the conceptual and the mechanism level, we have to be sure that it gives enough insight and clarity that national policy makers are able to follow the policy guidelines without transforming the opportunities offered by it into tools of political struggle at the national level. 


\section{Polarisation Viewed by Member State Policy-Makers}

It would be mistaken to believe that national policy makers do not consider reducing spatial inequalities a priority for their government. Regardless of the country specific context, national level policy-makers within the CEE region do devise instruments to reduce intra and inter-regional disparities. The question remains, however, how effective are those policies and what can be done to improve them?

It is often the case that policies devised by national authorities are based on strict economic analysis and neglect the complexity of uneven development. In Romania for example, national policies aimed at reducing disparities within the regions in fact have widened the gap. National policy-makers chose to focus on developing core cities, hoping for positive spillovers to foster development throughout the region. Discussed in detail by Benedek, Varvari and Litan, it seems that sustaining large urban agglomerations does not reduce peripheralisation within counties with large urban centres. On the contrary, this approach seems to have contributed to the widening of regional inequalities. Hungarian housing policy offers another example of a national-level policy that reproduces socio-economic discrepancies regardless of the assumed goal of reducing them. As presented by Posfai and Jelinek, Hungarian housing-related benefits are socially but not spatially distributed; however, the management of these benefits is delegated to local municipalities, which, due to a lack of national scale engagement, reproduces spatial discrepancies. Overall, the authors argue that housing policies in Hungary, as they work currently, promote home ownership in the peripheries of the core for the upper middle class. In this way, the policy simply perpetuates existing spatial inequalities that exclude from the scheme those people who need housing benefit the most.

These two examples point to a structural problem when analysing national-level policies. Often these are designed with shortterm political gains in mind. Given the ambiguity of EU-level policy mechanisms, it is left for national-policy makers to formulate policies that promote territorial and social convergence. 
National political actors are also tied to specific electoral cycles, so the immediate results may surpass long-term effects once a policy is designed. A couple of improvements could be made here to ensure more impactful policies to reduce regional and social disparities. Firstly, in the case of EU funds, national policy makers must ensure that Cohesion Policy goals are also clearly formulated within every national policy. In this way, the guiding principle of national-level policies should also coincide with the outlined goals of Cohesion Policy. Secondly, moving beyond the policy design stage, national authorities have to get more actively involved in regional development. This could be ensured by bringing together national and local authorities, representatives of the non-governmental sector and civic organisations in order to analyse and change implemented policies. National-level policy making is crucial in bridging the gap between EU-level policy goals and local implementation and acceptance of these goals. National-level policy makers are here probably the most important link in promoting (or even compromising) the idea of even development.

\section{$4 \quad$ Local-level Policy Effects and Pushbacks}

Regional and local actors are rarely considered active policy-makers, least so in CEE countries. Given the lack of serious policy mechanisms, their role is often a practical one, accessing funding from the national level and complying with policy requirements. It is important, however, to consider this administrative level as true reflection of a policy's efficiency and success. It is often down to regional or local actors to implement the policy and observe the changes it produces.

In some cases, local actors assume an active role in changing the situation of their locality. This is often viewed as healthy and beneficial; local leadership is, therefore, praised by national authorities and considered to be a driver for locally based development. While certainly valuable, local leadership also gives national authorities an excuse to shift the responsibility for structural problems to local actors. This issue is well described by Plüschke-Altof and Grootens discussing the Estonian 
context where, in some areas, local leadership assumes an important role in shaping the image of the locality, trying to move beyond the periphery label. This active involvement offers at the same time an ideal opportunity for national policy makers to shift the responsibility to the local level thereby minimising the importance of their involvement and overlooking structural problems that cannot be solved at the local level.

The role played by national authorities is of utmost importance since no real progress can be made without structural changes and substantial support for less developed regions. As pointed out by Graffenberger, inclusive access to high-performance information and telecommunication technology (ICT) must be considered a major component of (national) infrastructural as well as regional development policy. In this respect, national authorities have to assume an active role in ensuring a dense network of connections within and especially outside the region for local actors since it could foster local development, exchange of ideas and experiences and further the innovation capacities of these actors.

While in some cases local leadership is effective and welcomed, more often than not local communities are deprived of real political or economic instruments to influence local development processes. This is a very serious challenge for local development throughout the CEE region. If policies follow a strict top-down logic, with only national authorities deciding what type of projects better fit regional and local development, we risk ending up in situations where local authorities implement projects only for the sake of accessing funding, but lacking any serious impact on local development. As pointed out by Moldovan as well as by Cebotari and Mihaly, in the cases of Hungary and Romania, the policy direction designed by national authorities does not take into account local needs or the way those needs might be shaped. This is the reason some of the projects implemented through EU funding still fall short of reducing disparities between centres and peripheries.

While local actors rarely play an active part in the policy-making process, it is still important to consider them important to the policy process. A series of policy proposals could be formulated here to increase the involvement of local actors. The first thing to do is to support local leadership by taking a structural approach involving central, regional 
and local institutions. Simply considering local leaders as a good example does not suffice. State actors and policies have to provide a supportive environment for local action by investing in local infrastructure and providing a foundation for local actors and extra-regional actors to interact. By doing so, policies aiming to support local development have to consider a closer relationship with local authorities and the non-governmental sector. The design, implementation and evaluation of every policy should also involve local actors so that it ensures fitness to the local context.

\section{$5 \quad$ Policy Recommendations: Five Guiding Points}

Presenting the main challenges and possible alternatives to current administrative lines, we would like to suggest a series of five policy proposals that could contribute to improving the existing policy framework.

\section{Re-connecting Cohesion Policy to cohesion}

Cohesion Policy is one of the most powerful policy instruments available at the EU level that explicitly aims to reduce territorial disparities and promote even development. While it has strong financial backing and institutional support, Cohesion Policy encountered a series of challenges that had to be addressed in order to ensure its efficiency during the following programming periods. In that respect, we would like to advocate three major improvements that would strengthen the important role played by Cohesion Policy within the EU construct.

- Re-centre Cohesion Policy on the idea of spatial justice. As a pan-EU policy, Cohesion Policy must maintain a high degree of flexibility, ensuring adaptation to local contexts. This flexibility should rely on a clear understanding of the policy's main goal, which, in our opinion should draw from the idea of socio-economic justice and support. 
Clarifying this aim within the policy text should ensure consistency between the practical goal of the policy and the mechanisms it uses to achieve it.

- Open Cohesion Policy up for wider participation during the policy design stage. While member states are represented through the European Council, it is important that regions and intra-regional actors also get engaged throughout the policy design and evaluation stages. As there are different regional understandings of Cohesion Policy, it might be useful to integrate a wider range of views from regional leaders and local actors. Such an initiative would offer an alternative and complementary view on Cohesion Policy to the one formulated within the European Commission, EU Parliament or the Council of the EU. This would give wider legitimacy to the policy and lead to more coherence with the policy goals of regional leaders.

- Sustaining good governance and institutional capacity building beyond its commitment to support less developed regions, Cohesion Policy instruments must also encourage a specific type of development. Simple financial aid can encourage economic development. In order to maintain this development and diversify its effects into the social and political spheres as well, financial mechanisms must be combined with institutional support and sustainability goals. In this way, Cohesion Policy would also target lasting change within the less developed regions.

2. Increasing the participation of local and regional actors within national policy-making processes: let "place" also steer the design of policy

While local and regional actors are the main beneficiaries of regional development policies, they are also often excluded from decisionmaking processes. In addition to the standard public consultations, we suggest a series of three policy measures that could improve the participation of local actors, thereby granting the policies consistency, legitimacy and local input. 
- Establish a co-decision instrument to ensure shared input during the policy design stage. To do this, central authorities would have to establish a regional platform for discussion and consultation that would include, in addition to local authorities, non-governmental organisations, business representatives, civil society organisations, etc. Recommendations from this body could later serve as input for different regional based policy approaches.

- Reduce the required documentation and bureaucratic procedures related to funding applications for local actors. As a result of the complex requirements and limited capacities of local actors, they often avoid applying for EU funding. Simplifying the procedures and focusing on qualitative evaluation of projects would allow for more flexibility and understanding of local needs. To avoid the mismanagement of funds, the administrative burden should be given to national, regional and local authorities, leaving applicants to focus on the qualitative part of their project application. Another improvement would be ensuring a resilient online system for project pre-application. That would allow easier access to data for national authorities, an easier application process for local actors and a quicker evaluation process of the project proposals.

- Give local authorities more tools to steer and manage the EU and national funding. Given their connection and contextual understanding of the existing challenges, local authorities are probably best placed to consider the distribution of funds to support local development. Currently, local authorities have little to no tools to influence the way in which funds are managed and allocated. There have been many instances when local actors have accessed just for the sake of attracting more money to the locality. However, as we saw in the chapters of this book, in most cases these types of projects cannot produce locally based, long-lasting development.

3. National level engagement in building a supportive infrastructure at the regional and local level 
In order to create a supportive environment for locally based development, national authorities should be encouraged to go beyond policy frameworks and consider direct involvement to support expensive programs or to manage national programmes for which local authorities lack human and financial capital.

In some cases, such a presence could be translated into state-owned social housing in less well off areas, thus offering affordable housing to lower income inhabitants. It is also important to consider increased support for educational and healthcare services in these areas since it is often beyond the capacities of local authorities to provide appropriate incentives for qualified personnel to move to less developed areas. Hence, there is a need for the central government to step in and ensure support for them.

Another effective way to encourage local participation and to develop remote localities is to provide the required infrastructure and networking possibilities at the local level. We highlight here the clear need for investments in ITC and networking infrastructures at the regional level to promote inter-regional exchange and cooperation. Access to an effective ITC infrastructure would allow local agents to connect with agents from across the region as well as national legislators at the EU level. This would enable local actors to increase their visibility, to acquire outside knowledge and experience, to connect to possible suppliers or customers and in the end to ensure locally based development.

\section{Increasing human capital at the local level}

The basis for sustainable development is local capital, financial and human capital being equally important for local communities in order to change the dynamics of peripheralisation. While financial capital can be 'outsourced,' local human capital is crucial to realising lasting local development. It can serve as a foundation for increasing participation, community level decision making, proper management of financial resources or strategic investments for longer periods of time. In order to boost local human capital, a few public policies could be considered: 
- Allow for training and educational activities within every project financed by the European Union. As we saw in some cases, while the financial part of the project is financed from national or EU funds, there are no financing opportunities for training of local actors to manage the project, write applications or offer technical support for project implementation.

- Encourage engagement within the community. Every project implemented should first of all prioritise local engagement. Outsourcing project-related activities also means outsourcing knowledge acquisition, innovation capacity and further project development. Hence, regardless of the project's goal, local-level engagement within every project activity should always be an underlying aim.

- Capitalise all existing local resources. As discussed previously, projects are rarely fit for specific local needs. This shortcoming should be addressed by looking at local resources in the first place. National and local authorities should first be encouraged to evaluate available local resources (natural, financial or human) and promote those initiatives or projects that rely more on local resources.

Local human capital must be a central priority for policy makers. By encouraging local knowledge and local engagement, we can promote increasing innovative capacity, wider public engagement and subsequent better usage of financial resources.

\section{Promote policy-making and programming at the local level}

The policy-making paradigm, as it is at the current moment, is hierarchic, with EU and national-level authorities designing the policies and the mechanisms to implement them. Regional or local actors are passive recipients of EU or governmental programmes with little to no say about them. As discussed in this chapter, while well intended a lot of these policies do not deliver the expected results; in some cases they even make existing discrepancies worse. This is hardly surprising since it is rather challenging to design policies in the central, metropolitan regions that would be effective and context-sensitive to remote, peripheralised localities. To address this issue, we believe that the current policy structure requires a series of changes. 
- Offer local communities the possibility to design and propose projects or programmes for implementation within the main policy framework that better fit their local needs and capacities. This could be accomplished by establishing a co-decision mechanism at the regional level and aggregating all proposals for a more targeted policy approach at the regional level or local level. In this way, local actors could become important within the national or even EU level policy-making framework.

- Allow for larger flexibility in fund usage at the local level through participative budgeting. Allowing local communities to get engaged at the financial management stage of the project, while also encouraging wide participation at the local level, could ensure higher levels of social capital and at the same time ensure a more effective way of spending the project money.

- Accept for consideration projects and proposals that go beyond the established framework. Given their peripheral location, small communities often need to reinvent themselves in order to attract and keep people. This assumes a different strategy than the one by the book,' so in this context, rural communities have to become innovative and creative in their own way. This can be ensured by investing in local educational activities and offering more tools for policy making and financial management to local actors.

It is important within the entire policy discourse that we change our way of communication. Remote, isolated and peripheralised local communities should not be viewed as 'subsidy requiring and dying places.' This understanding can be changed once we give local communities the possibility to become central in a different, alternative way. Only by starting with the movement of peripheries from the periphery at a conceptual level we can bring about de-peripheralisation processes.

Any successful policy approach to the problems of peripheralisation must consider the diversity of actors and institutions involved. Relying on this diversity and building on existing resources, the above five points could be used as a roadmap to ensure a structural approach is taken to address peripheralisation problems. 
Open Access This chapter is licensed under the terms of the Creative Commons Attribution 4.0 International License (http://creativecommons. org/licenses/by/4.0/), which permits use, sharing, adaptation, distribution and reproduction in any medium or format, as long as you give appropriate credit to the original author(s) and the source, provide a link to the Creative Commons license and indicate if changes were made.

The images or other third party material in this chapter are included in the chapter's Creative Commons license, unless indicated otherwise in a credit line to the material. If material is not included in the chapter's Creative Commons license and your intended use is not permitted by statutory regulation or exceeds the permitted use, you will need to obtain permission directly from the copyright holder. 